\title{
Research on School Educational Reform from the Perspective of Complexity Science
}

\author{
Naizhu Huang \\ Xiangnan University \\ Chenzhou, Hunan, 423000
}

\author{
Xiaoping Wang \\ Xiangnan University \\ Chenzhou, Hunan, 423000
}

\author{
Xiaoming $\mathrm{Li} *$ \\ Xiangnan University \\ Chenzhou, Hunan, 423000 \\ (Corresponding Author)
}

\begin{abstract}
School educational reform is a complicated and systematic project which requires us to study in a way of nonlinear thinking. School educational reform must pursue democracy and social justice as its moral responsibility and train students to be culture adaptors with critical awareness, educated people and problem-solvers with creativity. It should take actual problems into consideration to adopt non-coercive measures to make all people voluntarily take part in reform. Reformers should play a dual role in individualism and collectivism and maintain moderate tension between centralization and decentralization.
\end{abstract}

Keywords—school, school education, reform, complexity

\section{SCHOOL EDUCATIONAL REFORM: A COMPLICATED AND} SCIENTIFIC RESEARCH PERSPECTIVE

The current reform on school education encounters mounting difficulties. It is urgent to advance overall educational reform to promote healthy development of schools. Under the guidance of complexity theory advocated by postmodern philosophy, the overall educational reform should transform from simple thinking with linear, order and manipulative characteristics into complexity thinking with nonlinear, creation and self-organized characteristics. The reasons why various measures for educational reform launched in traditional school education fail is the extreme conservation of the system of school education. In conservative system, the way to treat education by organizational system, teachers' training, teaching and management and government decision makers is easy to maintain status quo. Or "our school educational reform and practice is experiencing a difficult battle without any achievements in the end. The solution is more about climbing to anther peak to see the whole view which means that a new thinking mode should be used in school educational reform than climbing to the peak to introduce more and better reform measures'[1]. Such new

Fund project: Theoretical and Practical Research on the Transformation and Development of Local Institutions of Higher Learning--A Case Study of Xiangnan University--established project of research on educational reform of Hunan institutions of higher learn ing in 2015 (Xiang Jiao Tong[2015] No. 291; Strategic Research on Applied Technology in Undergraduate Development--special project of Hunan provincial research institute of education (XJK015BJD011). thinking mode is the complexity one which holds that the cause-effect relationship is non-linear and hard to trace back, thus there are multiple contradicts and conflicts. While creative solution grows out of the interaction among various factors such as uncertainty, diversification and instability. The process of complicated educational reform does not present linear model with inflection. The development of school reform is intricate and complicated due to the relationship with each unique school. Reform is not only an urgent task for schools, but also schools' long-term social and historical responsibility.

\section{THE COMPLEXITY OF MORAL OBJECTIVE SELECTION FOR SCHOOL EDUCATIONAL REFORM}

School educational reform in any countries need to face an issue of moral objective selection, which means the reasons to reform school education. The complexity of moral objective lies in that some kind of power structure will be change: improving students' scholastic attainment as well as narrowing the gap between good students and bad students. American scholar Tyler maintains that educational philosophy is based on the following questions: "whether school should cultivate younger people to adapt to social status quo or have the revolutionary sense of mission to change the society?" [2] Brazilian educator Freire also points out that" there doesn't exit neutral educational process. Education is considered as a means to play a role in promoting younger generation to integrate to existing systematical logic or a means to practice freedom in which men and women treat the reality in a critical and creative manner and give full play to change their own world."[3] School educational reform must undertake a moral responsibility to pursue democracy and social justice, cultivate students to be cultural adapters with critical awareness and educated, highly self-transcendent and creative problemsolvers. Such people obtain correct knowledge on the true, the good and the beautiful on basis of which they judge their own and social virtue and shortcomings. They are unstoppable in learning and keenly aware of their own ignorance, insufficient strength and growth limitation but are adamant in their confidence. "There were three important thoughts of view on moral objective of school educational reform in history-improving democracy and equality, promoting social 
mobilization and increasing social efficiency"[4]. At present, the purpose of school educational reform in many countries is to increase social efficiency and the basis is Soros' economic fundamentalist theory which holds that only by adjusting educational system to meet the need of market can social and economic development be realized and educational system has always been regarded as deficiency in efficiency and effect, thus being hard to give full play its corresponding functions. Therefore, education should cultivate those people who can obtain maximal economic efficiency in free and competitive market. Such people with strong flexibility, adaptation and mobility can creatively use knowledge to solve new problems in work, be able to work independently in pressure, acquire global and trans-cultural communication ability and know the significance of lifelong learning. However, based on market economy which takes social efficiency as its target, school educational reform orients toward individualism. Social cohesion, stability and trust relationship decline. People cannot feel the direct bearing between increased economic income and happiness. It is no wonder that Adams said that "education is the most important factor for social development and one of unrealistic fairy tales in 20th century." Due to the advancement of globalization, the social efficiency in educational reform may ruin educational cause. It is the educational reform view with social equality as the core while taking social efficiency and mobility into consideration that saves education, is the measure to solve global plight in globalization and promotes global harmony and the core of educational philosophy of educator Dewey. School educational reform should take moral vision to pursue social equality, emphasize equal opportunity to receive education, cultivate citizens with democratic awareness and make them have independent views and take part in the construction of democratic society. It should attach importance to social and cultural function, holding that the main purpose of education is to cultivate citizens who can maximize their own potential rather than high-efficient workers. Of course, it does not deny the significance of professional training but includes it into the whole educational system so as to make education play its role in promoting democratic and unified society and highlight the function of the whole social development instead of the function of individual development. It is shown from the four objectives emphasized by the reform of core courses in the world renown Harvard University that the moral responsibility for school educational reform is to cultivate global citizens, develop students ability in adapting to changes, make them understand the moral facet of life and realize that they are both the product of cultural tradition and participators in creation of this tradition"[6].

\section{THE COMPLEXITY OF STRATEGIC SELECTION FOR SCHOOL EDUCATION REFORM}

School educational reform is a complicated and systematic project which is interactively influenced by the environmental factors inside and outside school educational system. In the aspect of school, these factors include school management, culture, curriculum, facilities, surroundings, the relationship with local administrative departments and intervention from local administrative departments on schooling. In the aspect of teachers, the factors include teachers' professional quality, educational concept, personality, psychological status, economic income, pressure, the relationship among teachers and between teachers and principals. In the aspect of students, the factors include students' understanding on life and society, their experience on schooling and the relationship with other students, teachers and parents. In the aspect of society and state, the factors include national educational policies, home education, family income, the relationship between parents, national politics, economy and science and technology. In addition, some unavoidable random factors also influence school educational reform such as adjustment on educational policies by government, transfer of key leader in reform, slow economic development, increased immigrants, invention of new technologies and social conflicts. Due to nonlinear coupling effect, these factors will have hundreds of different reactions. It is no use for school educational reform adopting simple top-down control. Effective school educational reform can only lie between excessive control and disorder. In particular in post modern society, although the reform process of school education is well-planned, it is still filled with unpredictable and unmanageable problems and opportunities which in turn will generate multiple derivations. It is inevitable for school educational reform to be nonlinear and unstoppable. We need to read Change Forces--Probing the Depths of Educational Reform written by Canadian scholar Michael Fullan to understand its essence in order to provide good measures for the advancement of school educational reform.

\section{A. It is possible to adopt compulsory measures for school educational reform, but it is better to have few such measures}

School educational reform can be conducted in a partial and all-round manner. As for some partial and relatively simple reform which does not require thinking and skills to implement measures such as reduction of examinations and supervisory control of teachers' office hours, school managers should realize educational goal by formulating compulsory measures to strengthen control. But what the complexity of school educational reform requires is teachers' skills, creative thinking and free behavior rather than compelling them to be technicians. In addition, compulsion cannot highlight their responsibility and capacity. At present, the main problem for school educational reform is excessive compulsory projects or the implementation of superficial projects without any consideration. Some complicated educational reform problems with great value such as equal opportunity for school education and students' independent and cooperative study require teachers to have new skills, behaviors, concepts and understanding. Of course, it is not meaningless for compulsion. Political power from high level can not only put necessary pressure on school reform but also provide various opportunities to legalize school reform.

\section{B. School educational reform is a journey not a blueprint}

It is impossible for reform to follow planned orbit to move forward. Sometimes it may move backward. The complexity of school educational reform is like a planned journey in which we are in a leaky boat sailing into water area without sea chart with a band of reneged sailors. Facing with unpredictable reform, the key to succeed lies in 
drawing a new map. Under such uncertain circumstance, study, anxiety, difficulty, conflict and fear for the future in all reform all exist, especially in the initial reform. Effective educational reform is just like effective life, a real journey in which as long as we get started, we can arrive at destinations

\section{School educational reform should take problems very seriously, because they are the friend of reformers rather than foes}

Einstein once said that finding problems is more important than solving them. School educational reform starts with finding problems. School leaders in poor performance of schooling always ignore, deny and suppress problems or lack the skills to find out problems. Avoiding real problems is the foe of effective reform. When facing problems, we should be innovative and bold in breaking through. Only by doing so can efficiency be achieved. Senge once said that 'teams in business tend to spend their time fighting for turf, avoiding anything that will make them look bad personally, and pretending that everyone is behind the team's collective strategy--maintaining the appearance of a cohesive team. To keep up the image, they seek to squelch disagreement; people with serious reservations avoid stating them publicly, and joint decisions are watereddown compromises reflecting what everyone can live with, or else reflecting one person's view foisted on the group. If there is disagreement, it's usually expressed in a manner that lays blame, polarizes opinion, and fails to reveal the underlying differences in assumptions and experience in a way that the team as a whole could learn."[6] School educational reform is a complicated process in and of itself, filling with various and unpredictable problems. Only with candid and brave attitude toward problems and by learning with open-minded and unremittingly searching measures to take actions to solve problems can reform stride a key step.

\section{The vision and strategic plan for school educational}

reform is gradually formed and clear in the reform process

School educational reform requires vision instead of immature and blindly-copied plans from books. Due to the complexity of school educational reform, it takes time and actual experience to form relative correct vision which stems from action rather than the one prior to it. It requires continuous modification and improvement due to its fleeting nature. It is essential for success to have shared vision which is gradually formed by interaction between members of organization and leaders' scheduling. Shared vision is an important feature for a learning-based organization. Its establishment is the key technique for schools to implement reform. Individual vision bases on moral objectives, exploration, control and coordination, while the formation of collective vision is a process of gradual deepening and increasing clarity, enthusiasm, communication and responsibility.

\section{E. School educational reform should give play to the dual strength of individualism and collectivism}

School educational reform sometimes needs to give play to leaders' own strength to guide people to move forward the journey of reform. But with limited personal strength and wisdom, reform requires individualism and collectivism to play a role, which means that effective school reformers not only cannot yield to small group interests but also need to overcome isolated reform state. Lortie pointed out that "teaching has always been considered as a lonely profession which restricts them to absorb new ideas and obtain better solutions. They bury pressure in their heart to aggravate and accumulate. They cannot recognize and appreciate success. They allow the existence of incapability and maintain such state as is not conducive to students, colleague and themselves. Even if loneliness doesn't happen very often, it is loneliness that allows the existence of conservation and rejection of educational reform [7].

Because loneliness brings limitation to reformers, school educational reform should advocate teachers cooperation and shared collective action based on diversification. As for complicated educational issues, schools which have coordinated relationship and are enriched by learning do better than those schools which remain isolated educational tradition. But extreme "small group idea" growing out of too close collaboration is not helpful to school reform, because it will cause uncritical compliance to groups, accept new resolution without any consideration and suppress different opinions. When developing extensive cooperation, reformers need to see the "benefit" of individualism. The ability in thinking and working independently is very important to educational reform. The newest ideas always come from diversification and marginalized persons in groups.

\section{F. School educational reform should guarantee moderate tension between centralization and decentralization}

Is it good to be centralization or decentralization for school educational reform? Han Feizi, an ancient scholar of China, advocated centralization in social governance that "unified central government takes control of legislative power and the power of central government is ultimately in the hands of the emperor'[8]. Aristotle, ancient Greek scholar, put forward the idea of decentralization. He divided state power into three aspects: legislative, executive and judicial branch respectively. Laozi, founder of Taoism, advocated the thought of governing without interruption in which "I will do nothing (of purpose), and the people will be transformed of themselves; I will be fond of keeping still, and the people will of themselves become correct. I will take no trouble about it, and the people will of themselves become rich; I will manifest no ambition and the people will of themselves attain to the primitive simplicity"[9]. School educational reform should lie between centralization and decentralization because centralization lacks of excessive control and decentralization will lead to chaos. Thus it makes sense to maintain moderate tension between centralization and decentralization which is similar with the thought of governing without interruption of Taoism and identical with the words of Senge "how to achieve the goal of control without adopting the method of control". 


\section{G. School educational reform needs to strive for support from everyone}

School educational reform is a complicated project which will become a terrible matter if it is manipulated only by experts or several leaders. Reformers should strive for all faculties to participate in reform by propaganda and promotion and become the impetus of school educational reform. In the past, our opinions on leaders are based on individual and unsystematic world view. We believe that they are extremely excellent figures and it is their duty to set orientation, make big decision and motivate employees. If such belief prevails, then the tendency of solving problems by personal charisma or short-term training will be strengthened and systematic and collective learning will be ignored. Learning-based organizations demand that each teacher has the responsibility to create the organizations which individual and collective are able to explore and update. General speaking, institutional culture cannot provide shortcut to the reform, nor benefits to the reform. More often than not, it serves the status quo or rejects reform. When we face school reform, it is vital to have individual and collective learning. We should keep learning to explore how to improve our work so as to promote the formation of individual new thinking mode and master new techniques for educational work. Formal organizational structure and system is the one which conduct final change when seeking rejuvenation rather than change in the first place assumed by most reformers, so does school educational reform. It should first start with minor, isolated and surrounding actions instead of major, collective and core actions. Minor and isolated scope reflects such reform as new behavior and attitude which will generate new ideas, thus promoting the change of structure and procedures.

Of course, school educational reform is not only about the issue of school itself, but has extensive connections with family, society and government. As it were, it is impossible for educational reform to be successful only launched by school. Therefore, it should do two things well for school educational reform: first, the personal moral objective of teachers must connect with bigger social interests. Teachers should focus on students' achievements and take part in the reform of school to create the most effective environment to help students study. And teachers must seek opportunities to cooperate with others and realize that they should work with students and their parents to develop learning-based school. Second, in order to be successful, schools must actively analyze their surroundings and response to and contribute to current issues of society so as to obtain broad support from society for school reform.

\section{CONCLUSION}

School educational reform is a complicated and systematic project which requires us to study in a way of nonlinear thinking. In order to guarantee good result of school educational reform, it should promote comprehensive educational governance in an all-round manner under the guidance of systematic thinking. School educational reform must pursue democracy and social justice as its moral responsibility and train students to be culture adaptors with critical awareness, educated people and problem-solvers with creativity. The path for school educational reform is diversified but it must take the problem-solving as its core and adopt noncoercive measures to make all people voluntarily take part in reform. Reformers should play a dual role in individualism and collectivism and maintain moderate tension between centralization and decentralization.

\section{ACKNOWLEDGEMENT}

Fund project: Theoretical and Practical Research on the Transformation and Development of Local Institutions of Higher Learning--A Case Study of Xiangnan University-established project of research on educational reform of Hunan institutions of higher learning in 2015 (Xiang Jiao Tong[2015] No. 291; Strategic Research on Applied Technology in Undergraduate Development--special project of Hunan provincial research institute of education (XJK015BJD011).

\section{REFERENCES}

[1] Michael Fullan, Change Forces--Probing the Depths of Educational Reform[M]. Beijing: Educational Science Publishing House, 2004, 8.(In Chinese)

[2] Ralph tyler, Basic principles of Curriculum and Instruction (Chicago: University of Chicago press, 1949), p.35.

[3] Paulo Freire, Pedagogy of the Oppressed (New York: Seabury Press, 1973) , p.15.

[4] Labaree, D. (2003) How to Succeed in School without really learning: The Credential race in American education, New Haven: Yale University Press.

[5] Xue Yong, Cultivating Elite[M].Jiangsu Literature and Art Publishing. Ltd, 2010: 144.(In Chinese)

[6] Senge, p. (1990) The Fifth Discipline, New York, Doubleday.p.24.

[7] Lortie, D. (1975) School Teacher: A Sociological Study, Chicago IL, University of Chicago Press.

[8] Han Feixi. Han Feizi- Property Right. (In Chinese)

[9] Laozi The Book of Tao and Teh- Chapter 57. (In Chinese) 